\title{
Apoptosis triggered by vitexin in U937 human leukemia cells via a mitochondrial signaling pathway
}

\author{
CHAO-YING LEE ${ }^{1}$, YUNG-SHIN CHIEN ${ }^{2}$, TAI-HUI CHIU ${ }^{1}$, WEN-WEN HUANG ${ }^{3}$, \\ CHI-CHENG LU ${ }^{4}$, JO-HUA CHIANG ${ }^{4}$ and JAI-SING YANG ${ }^{2}$

\begin{abstract}
${ }^{1}$ School of Pharmacy, Departments of ${ }^{2}$ Pharmacology, and ${ }^{3}$ Biological Science and Technology, China Medical University; ${ }^{4}$ Department of Life Sciences, National Chung Hsing University, Taichung, Taiwan, R.O.C.
\end{abstract}

Received May 16, 2012; Accepted July 24, 2012

DOI: $10.3892 /$ or.2012.2000

\begin{abstract}
Vitexin, a lignan compound, has been shown to exert apoptotic actions on human breast cancer cell lines and to have anti-inflammatory activities. Nevertheless, there is currently no study addressing the effects of vitexin on the induction of apoptosis in U937 human leukemia cells. The aim of this study was to determine the anticancer effects and molecular mechanisms of vitexin on U937 leukemia cells. We showed that vitexin can potently induce programmed cell death in U937 leukemia cell growth as well as morphological changes that were examined by MTT assay and phase contrast microscopy, respectively. The DNA content and the levels of mitochondrial membrane potential $(\Delta \Psi \mathrm{m})$ were determined by flow cytometric analysis. The cell cycle arrest-regulated and apoptosis-associated protein levels were measured by western blotting. Vitexin-triggered apoptosis was accompanied by a decrease of the level of $\Delta \Psi \mathrm{m}$ and the percentage of viability and provoked apoptosis in U937 cells. The downregulation of the protein level for Bcl-2 with the simultaneous upregulation of caspase-3 and -9 protein expression in U937 cells were observed after treatment with vitexin. Therefore, our data provide a potential mechanism for the chemopreventive activity of vitexin, and we suggest that vitexin may serve as a therapeutic agent for the treatment of human leukemia.
\end{abstract}

\section{Introduction}

Approximately four per 100,000 people succumb to leukemia each year in Taiwan, according to reports from the Department of Health, Executive Yuan of Taiwan $(1,2)$. The current primary treatment for leukemia is chemotherapy, however the survival rates remain unsatisfactory. Acute myeloid leukemia (AML) increases the number of myeloid cells in the bone marrow

Correspondence to: Dr Jai-Sing Yang, Department of Pharmacology, School of Medicine, China Medical University, 91 Hsueh-Shih Road, Taichung 40402, Taiwan, R.O.C.

E-mail: jaising@mail.cmu.edu.tw

Key words: vitexin, apoptosis, U937 human leukemia cells, intrinsic signaling, caspase-3 and interrupts their maturation, resulting in hematopoietic insufficiency (3-5). Differentiation induction, as a therapeutic strategy, can have a powerful impact on hematopoietic malignancies, in particular on myeloid leukemia $(6,7)$. Therefore, discovering a new antileukemia agent that is more effective and less toxic for leukemia patients is necessary.

Vitexin is a natural apigenin flavone glucoside, found in the Desmodium species $(8,9)$. It has been reported to exhibit biological activities, including antioxidant and antiinflammatory effects (8). Vitexin is now known to also possess antitumor activities by targeting apoptotic cell death in human breast cancer cell lines and potent inhibition on tumor necrosis factor $\alpha$ (TNF- $\alpha$ )-induced cell death (10). Therefore, our study investigated the effects of vitexin on the induction of apoptosis in U937 human leukemia cells.

Apoptosis assures the homeostasis of tissues during development, host defense and aging $(11,12)$. Divergent cell survival due to insufficient apoptosis has been linked to the development and/or progression of human malignancies (13). Nevertheless, cancer cells with mutations or abnormalities in the expression of other genes that regulate apoptosis can display intrinsic resistance to chemotherapy-induced apoptosis $(11,14)$. This suggests that acquired defects in the apoptotic process play an important role in the development of drug resistance. In addition, several transcription factors have been shown to be targets of vitexin action, which may mediate vitexin-induced programmed cell death (15). This study investigated whether vitexin could induce cell apoptosis in U937 human leukemia cells, as there is currently no available information regarding its cytotoxic effects on human leukemia cells.

\section{Materials and methods}

Chemicals and reagents. Vitexin (Fig. 1), dimethylsulfoxide (DMSO), propidium iodide (PI), 3-(4,5-dimethylthiazol-2-yl)2,5-diphenyltetrazolium bromide (MTT), RNase A, Triton $\mathrm{X}-100$ and cyclosporine A were purchased from Sigma-Aldrich Corp. (St. Louis, MO, USA). All primary and secondary antibodies were obtained from Santa Cruz Biotechnology Inc., (Santa Cruz, CA, USA). TE buffer (10 mM Tris-HCl, $1 \mathrm{mM}$ EDTA, pH 7.6), potassium phosphates and z-VAD were purchased from Merck Co. (Darmstadt, Germany). RPMI-1640 medium, fetal bovine serum (FBS), penicillin-streptomycin 
and L-glutamine were obtained from Gibco/Life Technologies (Grand Island, NY, USA). All of the chemicals used were of reagent grade.

Cell cultures. The human lymphoma U937 cell line was purchased from the Food Industry Research and Development Institute (Hsinchu, Taiwan, R.O.C.). The cells were grown in RPMI-1640 medium supplemented with $10 \%$ heat-inactivated FBS, $100 \mu \mathrm{g} / \mathrm{ml}$ penicillin- $100 \mathrm{U} / \mathrm{ml}$ streptomycin and $2 \mathrm{mM}$ L-glutamine, and grown in a humidified $5 \% \mathrm{CO}_{2}$ atmosphere at $37^{\circ} \mathrm{C}$. The cells were subcultured every third day (16).

Cell viability and morphological changes. The U937 human leukemia cells were placed in 96-well cell culture plates at an initial concentration of $1 \times 10^{4}$ cells $/ \mathrm{ml}$ and incubated with various concentrations of vitexin $(0,50,100,200$ and $400 \mu \mathrm{M})$. After a $24-\mathrm{h}$ incubation period, MTT solution $(0.5 \mathrm{mg} / \mathrm{ml})$ was added into the wells for $4 \mathrm{~h}$. The growth medium was removed, and the formazan crystals formed by oxidation of the MTT dye were dissolved with $100 \mu 10.04 \mathrm{~N} \mathrm{HCl}$ in isopropanol. The absorbance was measured at $570 \mathrm{~nm}$ by ELISA reader and the cell survival ratio was expressed as a percentage of the control as previously described $(17,18)$. For morphological changes, cells were cultured in 12-well plates at a density of $2 \times 10^{5}$ cells/well and treated with or without $200 \mu \mathrm{M}$ of vitexin for $24 \mathrm{~h}$. Morphological changes in vitexin-treated cells were examined and photographed using phase-contrast light microscopy (19). All results were obtained from three independent experiments.

DNA laddering fragmentation assay. Approximately $2 \times 10^{5}$ cells/well of U937 cells were grown in 12-well plates and treated with vitexin or vitexin plus z-VAD (a pan-caspase inhibitor) for $24 \mathrm{~h}$. DNA was extracted from vitexin-treated and untreated cells with the Tissue and Cell Genomic DNA purification kit (Genemark Technology Co., Ltd. Tainan, Taiwan). DNA fragmentation was visualized by $1.5 \%$ agarose gel electrophoresis as previously described $(20,21)$.

Flow cytometric analysis for apoptosis by TUNEL assay. TUNEL staining was performed according to the manufacturer's protocols (in situ cell death detection kit; Roche Diagnostics, Boehringer Mannheim, Germany). Cells (1x10 $/$ well) were individually plated into six-well plates and exposed to $1 \mu \mathrm{M}$ vitexin and vitexin plus z-VAD or cyclosporine A (a mitochondrial membrane potential inhibitor) for $24 \mathrm{~h}$. After treatment, cells were collected and fixed in $4 \%$ formaldehyde overnight, placed in $0.1 \%$ Triton X-100/PBS, washed with $0.1 \%$ PBS twice, then stained with $100 \mu 1$ of terminal deoxynucleotidyl transferase-containing solution and incubated in the dark for $30 \mathrm{~min}$ at $37^{\circ} \mathrm{C}$. Following TUNEL staining, all samples were washed three times and resuspended in $0.5 \mathrm{ml}$ of PBS containing PI $(10 \mu \mathrm{g} / \mathrm{ml})$ and DNase free-RNase A ( $200 \mu \mathrm{g} / \mathrm{ml})$. TUNEL-positive cells were analyzed by flow cytometry. The median fluorescence intensity was quantified with CellQuest software (BD Biosciences) $(21,22)$. TUNEL assays were performed in triplicate for three independent experiments.

Caspase activity determinations. Caspase activity in cell lysates was measured using the manufacturer's protocols (caspase-3,-7<smiles>O=c1cc(-c2ccc(O)cc2)oc2c(C3OC(CO)[C@H](O)C(O)[C@H]3O)c(O)cc(O)c12</smiles>

Vitexin: $\mathrm{C}_{21} \mathrm{H}_{20} \mathrm{O}_{10}$

Figure 1. Chemical structure of vitexin.

and -9 colorimetric assay kits; R\&D Systems Inc., Minneapolis, MN, USA). Cells were re-suspended in medium at an initial concentration of $5 \times 10^{6}$ cells and pelleted and re-suspended in $0,50,100,200$ and $400 \mu \mathrm{M}$ of vitexin for $24 \mathrm{~h}$. Cells were lysed in lysis buffer [50 mM Tris- $\mathrm{HCl}$ (pH 7.4), 1 mM EDTA, $10 \mathrm{mM}$ EGTA, $10 \mathrm{mM}$ digitonin and $2 \mathrm{mM}$ DTT]. The cell lysates (50 $\mu \mathrm{g}$ proteins) were incubated with caspase- $3,-7$ and -9 specific substrates (Ac-DEVD-pNA and Ac-LEHD-pNA) at $37^{\circ} \mathrm{C}$ for $1 \mathrm{~h}$. Caspase activity and absorbance were measured with an enzyme-linked immunosorbent assay reader at $\mathrm{OD}_{405}$ $(16,23)$. All results are from three independent experiments.

Measurement of mitochondrial membrane potential. Cells were seeded in 24-well cell culture plates at an initial concentration of $2 \times 10^{5}$ cells $/ \mathrm{ml}$ and were maintained with $0,50,100$, 200 and $400 \mu \mathrm{M}$ of vitexin for $24 \mathrm{~h}$. Flow cytometry was then used to determine the level of $\Delta \Psi \mathrm{m}$. Following incubation, cells were harvested, washed twice by PBS, and then stained with $500 \mu \mathrm{l}$ of $100 \mathrm{nM}$ of $\mathrm{DiOC}_{6}$ that was stored at $-20^{\circ} \mathrm{C}$ as a $1 \mu \mathrm{mol} / 1$ stock in DMSO for the level of $\Delta \Psi \mathrm{m}$. Subsequently, cells were maintained in a dark room for $30 \mathrm{~min}$ at $37^{\circ} \mathrm{C}$ and all samples were analyzed immediately by flow cytometry, as previously described $(19,24)$.

Western blot analysis. Western blot analysis to determine the levels of various proteins was performed as previously described $(18,19)$. Cells were washed with PBS and lysed into the PRO-PREP ${ }^{\mathrm{TM}}$ protein extraction solution (iNtRON Biotechnology, Gyeonggi-do, Korea) before being placed in a $10-\mathrm{cm}$ dish at an initial concentration of $1 \times 10^{7}$ cells and incubated with $200 \mu \mathrm{M}$ of vitexin for $6,12,18$ and $24 \mathrm{~h}$. An equal amount of cell lysate was separated by $10 \%$ gel using sodium dodecyl sulphate-polyacrylamide gel electrophoresis (SDS-PAGE). Proteins were electro-transferred to a nitrocellulose membrane using iBot Dry Blotting system (Invitrogen/ Life Technologies). The membrane was then blocked in 5\% powdered non-fat milk in PBST solution $(0.1 \%$ Tween-20 in PBS) for $1 \mathrm{~h}$. The primary antibodies caspase-9, caspase-3 and $\mathrm{Bcl}-2$ were diluted in blocking solution and then incubated with the membrane overnight. The membrane was then covered with an alkaline HRP conjugated secondary IgG antibody (goat anti-rabbit and goat anti-mouse) for $1 \mathrm{~h}$. After incubating with the second antibody, the membranes were reacted with enhanced chemiluminescence (ECL) solution (Western blotting 
A

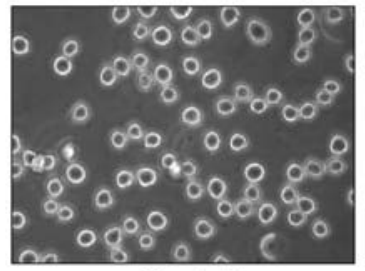

Control

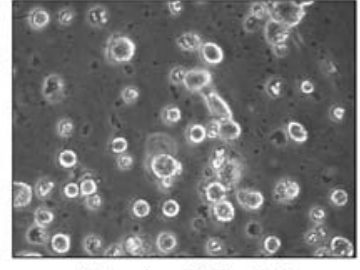

Vitexin $(200 \mu \mathrm{M})$
B

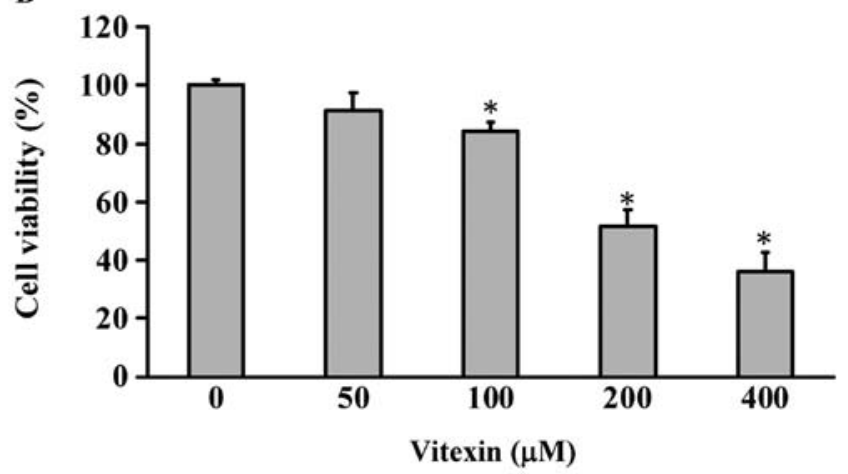

Figure 2. Effects of vitexin on morphological changes and cell viability in U937 human leukemia cells. (A) Morphological changes of U937 cells treated with $200 \mu \mathrm{M}$ vitexin for $24 \mathrm{~h}$. Photomicrographs of vitexin-treated or -untreated cells were taken by an inverted microscope at 200x magnification. Representative images are taken from three independent experiments. (B) Following treatment with 0, 50, 100, 200 and $400 \mu \mathrm{M}$ of vitexin for $24 \mathrm{~h}$, the cell viability of U937 cells were shown and determined by MTT assay. Data represent the mean \pm SD of three experiments. ${ }^{*} p<0.05$ denotes statistically significant differences compared with untreated control.

detection kit, Immobilon Western HRP substrate, Millipore, Billerica, MA, USA). Signals were detected by X-ray film (GE Healthcare, Piscataway, NJ, USA). $\beta$-actin was included as a loading control. The radiograms were scanned and the band density was quantified using NIH ImageJ program (Bethesda, MD, USA) (18).

Statistical analysis. Data were expressed as the mean \pm SD and differences between control and vitexin-treated groups were analyzed by Student's t-test. ${ }^{*} \mathrm{p}<0.05$ was considered to indicate statistically significant differences.

\section{Results}

Effects of vitexin on morphological changes and cell viability of U937 human leukemia cells. The morphological changes shown in Fig. 2A indicate that the cells in the vitexin-treated and the control group differ significantly. Some of the cells detached from the surface and debris were also observed in the plate of the vitexin-treated group, but the control cells were well spread with flattened morphology (Fig. 2A). To determine the growth inhibition effects of vitexin, cells were treated with different concentrations $(50,100,200$ and $400 \mu \mathrm{M})$ of vitexin for $24 \mathrm{~h}$. Cell viability was determined by the MTT assay. Concentration- and time-dependent effects of vitexin are shown in Fig. 2B, and the viable cells were significantly reduced in the vitexin-treated U937 human leukemia cells. The concentration required to inhibit growth by $50 \%\left(\mathrm{IC}_{50}\right)$ for $\mathrm{U} 937$ human leukemia cells was $\sim 200.34 \mu \mathrm{M}$ at $24 \mathrm{~h}$. We suggest that vitexin

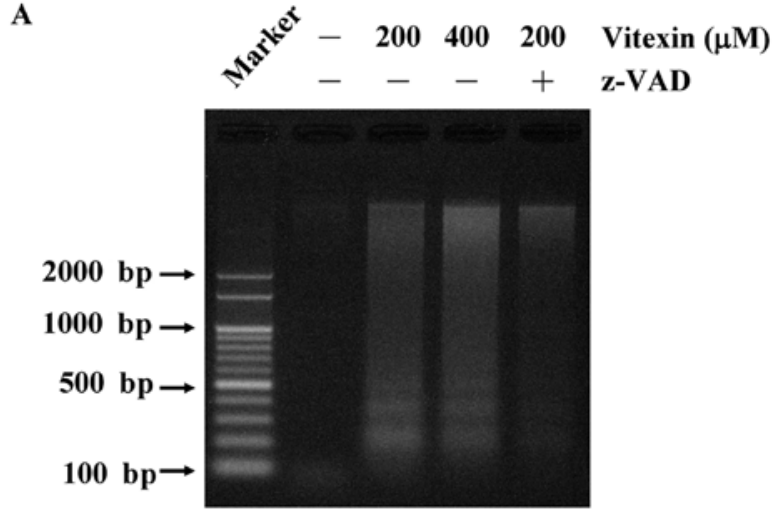

B

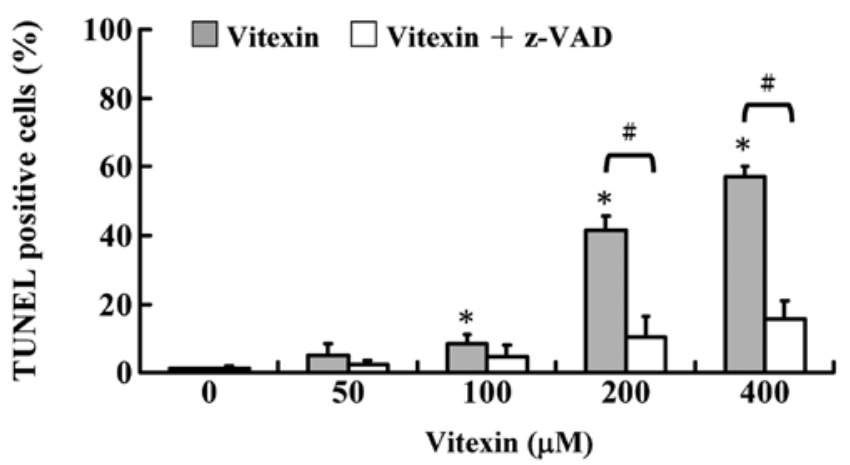

Figure 3. Effects of DNA fragmentation and the TUNEL positive cells on U937 cells following vitexin in the presence or absence of z-VAD. (A) Vitexin induced an apoptotic process characterized by DNA fragmentation. Agarose gel electrophoresis of DNA extracted from U937 cells. (B) Cells were treated with vitexin at various concentrations $(0,50,100,200$ and $400 \mu \mathrm{M})$ in the presence or absence of z-VAD for $24 \mathrm{~h}$ as described in Materials and methods. Each point is the mean \pm SD of three experiments. ${ }^{*} \mathrm{p}<0.05$ denotes statistically significant differences compared with untreated control. ${ }^{*} \mathrm{p}<0.05$ denotes statistically significant differences compared with untreated z-VAD.

reduced the proportion of viable U937 human leukemia cells in a concentration- and time-dependent manner.

Effects of DNA laddering fragmentation in U937 cells. DNA laddering provides evidence for a vitexin-induced apoptotic process characterized by DNA fragmentation. The agarose gel electrophoresis of DNA extracted from U937 cells treated with vitexin at various concentrations (200 and $400 \mu \mathrm{M})$ for $48 \mathrm{~h}$ was carried out and the results revealed that DNA fragmentation occurred in vitexin-treated U937 cells (Fig. 3A). We also noted that pretreatment with z-VAD (a pan-caspase inhibitor) is likely to protect a vitexin-provoked DNA ladder of U937 cells. Similarly, TUNEL positive cells were also observed in U937 cells after exposure to 100, 200 and $400 \mu \mathrm{M}$ of vitexin, and $\mathrm{z}$-VAD attenuated vitexin-induced TUNEL positive cells in comparison to untreated control cells, as shown in Fig. 3B. Thus, vitexin concentration-dependently induced apoptosis by DNA fragmentation. Based on this finding, we suggest that vitexin-induced apoptotic death of U937 cells is correlated with caspase-dependent effects.

Effects of vitexin on the caspase-3, -7, and -9 activities in U937 cells. We determined the roles of individual caspases in 

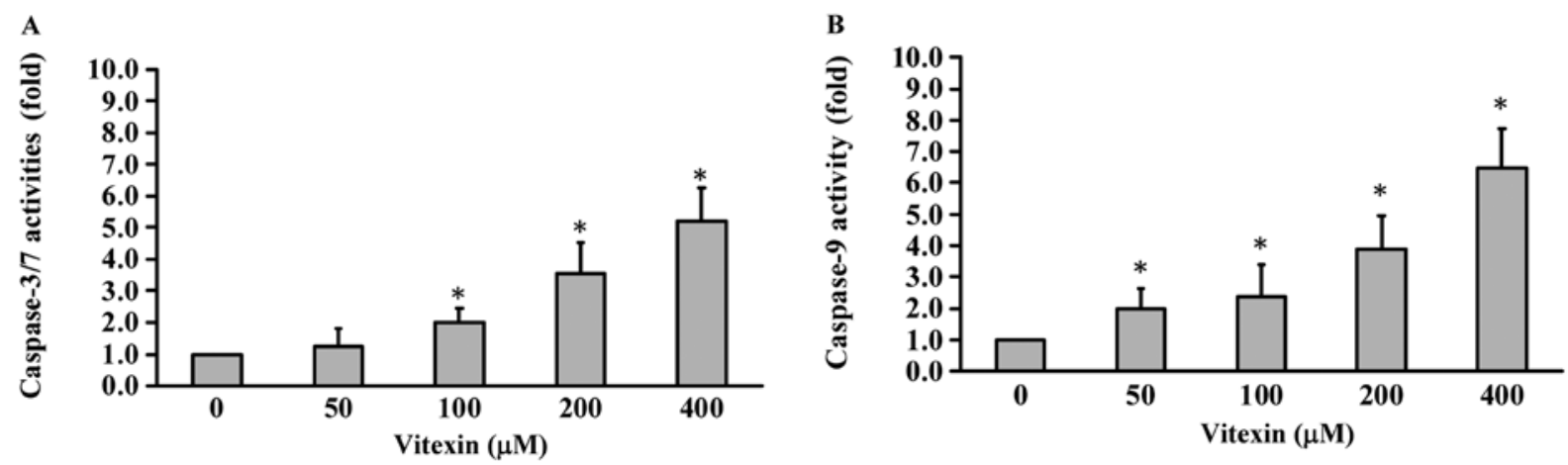

Figure 4. Effects of caspase-3, -7 and -9 activities on vitexin-treated U937 cells. The activities of (A) caspase-3, -7 and (B) caspase-9 in U937 cells after treatment with vitexin at various concentrations $(0,50,100,200$ and $400 \mu \mathrm{M})$. Cells were then collected to add each substrate solution for caspase-3, -7 and -9 activity determination according to the manufacturer's instructions as described in Materials and methods. Data represent the mean \pm SD of three experiments. $* \mathrm{p}<0.05$ denotes statistically significant differences compared with untreated control.
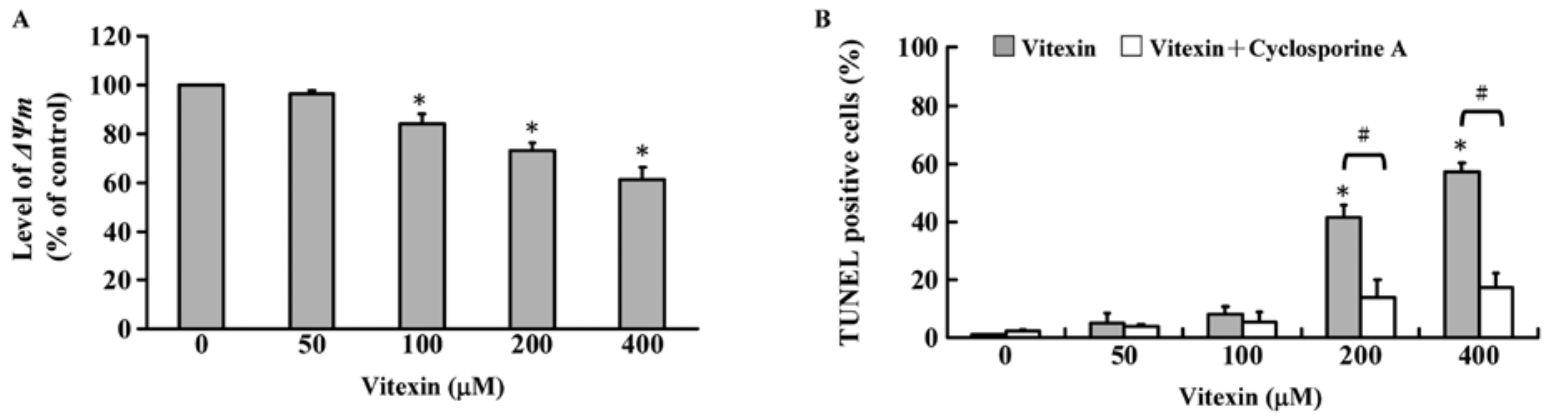

Figure 5. Effects of mitochondrial membrane potential $(\Delta \Psi \mathrm{m})$ and TUNEL positive cells in U937 cells after treatment. Cells were exposed to vitexin at various concentrations $(0,50,100,200$ and $400 \mu \mathrm{M})$ for $24 \mathrm{~h}$ and then harvested for measuring the level of $\Delta \Psi \mathrm{m}$ as described in the Materials and methods. (A) The levels of $\Delta \Psi \mathrm{m}$ were determined by flow cytometry and quantified using BD CellQuest Pro software. (B) Vitexin at various concentrations in the presence or absence of cyclosporine A affected the TUNEL positive cells. Data represent the mean \pm SD of three experiments. *p $<0.05$ denotes statistically significant differences compared with untreated control. " $\mathrm{p}<0.05$ denotes statistically significant differences compared with untreated $\mathrm{z}$-VAD.

A Vitexin $(200 \mu \mathrm{M}) \frac{6 \mathrm{~h}}{-+} \frac{12 \mathrm{~h}}{-+} \frac{18 \mathrm{~h}}{-+} \frac{24 \mathrm{~h}}{-+}$

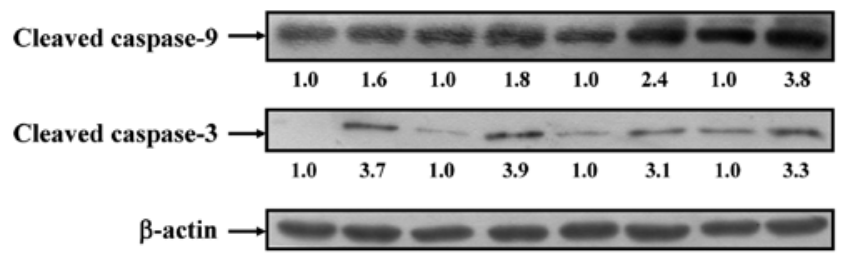

B

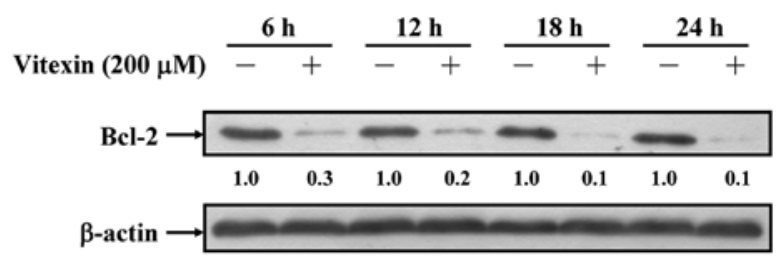

Figure 6. Effects of apoptosis-associated protein expression in U937 cells after vitexin treatment. Cells were treated with $200 \mu \mathrm{M}$ vitexin for 6, 12,18 and $24 \mathrm{~h}$ and then harvested for western blotting to examine the protein levels of (A) cleaved caspase-3 and cleaved caspase-9, and (B) Bcl-2, as described in Materials and methods. Data are representative of three independent experiments that yield similar results.

vitexin-induced apoptosis. In order to evaluate the effects of vitexin on the activities of caspase-3, -7 and -9 in U937 cells, caspase activity assays were applied to investigate related caspase activities. The results in Fig. 4A and B show that various concentrations $(0,50,100,200$ and $400 \mu \mathrm{M})$ of vitexin promoted caspase-3, -7 (Fig. 4A) and caspase-9 (Fig. 4B) activities in a concentration-dependent manner. We confirm that vitexin-induced apoptosis is mediated by activations of caspase-3, -7 and -9 signaling. Thus, we suggest that intrinsic apoptotic signaling contributed to vitexin-triggered apoptosis of U937 cells in vitro.
Effects of vitexin on mitochondrial membrane potential and its inhibitor (cyclosporine A) in U937 cells. Cells were treated with $50,100,200$ and $400 \mu \mathrm{M}$ of vitexin for $24 \mathrm{~h}$. The alterations of $\Delta \Psi \mathrm{m}$ were determined by staining with $\mathrm{DiOC}_{6}$ and then analyzed by flow cytometry, and representative data are shown in Fig. 5A demonstrating that vitexin decreased the level of $\Delta \Psi \mathrm{m}$ in U937 cells and this effect is a concentrationdependent response. To explore whether vitexin-induced apoptosis is mediated through mitochondrial depolarization, cyclosporine A (a $\Delta \Psi \mathrm{m}$ inhibitor) was used for measuring TUNEL positive cells. We found that cyclosporine $\mathrm{A}$ is able to 


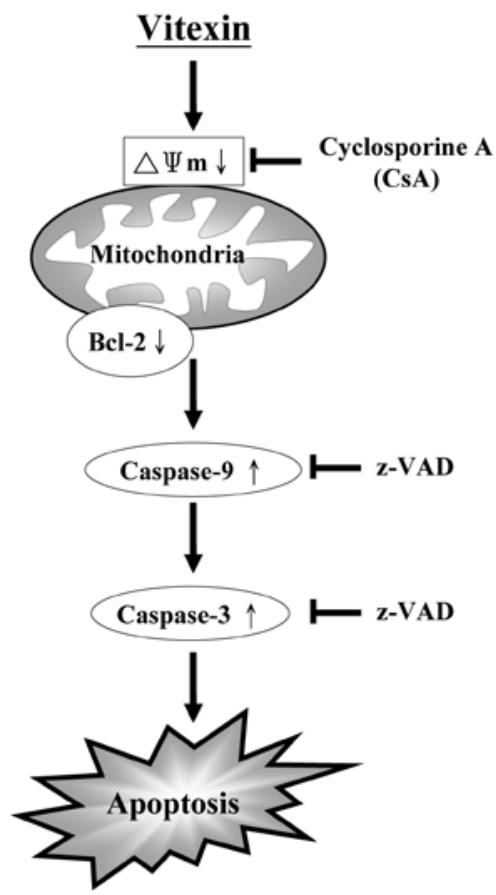

Figure 7. The proposed mechanism of vitexin-triggered apoptotic death of U937 human leukemia cells. The flow chart shows that vitexin-induced apoptosis through the mitochondrial pathway and caspase-3-dependent signaling in U937 cells in vitro.

decrease vitexin-stimulated apoptosis in U937 cells as seen in Fig. 5B. We suggest that vitexin-induced apoptosis is involved in the mitochondrial signaling pathway.

Effects of vitexin on the levels of apoptosis-associated protein expression in U937 cells. We confirmed that vitexin-induced apoptosis is associated with mitochondria-dependent protein expressions. Our data indicate that vitexin promoted the expressions of cleaved caspase- 3 and cleaved caspase- 9 in U937 cells (Fig. 6A). The Bcl-2 family proteins located on the mitochondrial membrane are important for suppression of mitochondrial manifestations of apoptosis $(12,16)$. Fig. 6B shows that a decrease of Bcl-2 expression occurred in vitexin-treated U937 cells. Consequently, the induction of the mitochondrial pathway plays a central role in vitexin-induced apoptosis of U937 cells in vitro.

\section{Discussion}

Vitexin, a natural apigenin flavone glucoside, has been reported to exhibit antioxidative and anti-inflammatory properties, and to have growth inhibitory effects in human breast cancer cell lines $(9,25)$, but few reports demonstrate its inhibitory effects on U937 human leukemia cells. In this study, we found that different concentrations $(50,100,200,400 \mu \mathrm{M})$ of vitexin significantly inhibited the growth of U937 human leukemia cells (Fig. 2B). These data indicate that vitexin inhibited cell proliferation and induced apoptosis (Fig. 3) in the U937 human leukemia cells, and vitexin induced morphological changes (Fig. 2A) and reduced the percentage of viable cells in the human U937 leukemia cell in a dose- and time-dependent manner.
It is well known that mitochondria are implicated as being a center mechanism and one of the apoptotic targets $(26,27)$, and Bcl-2 family protein expression is likely to influence mitochondrial depolarization (28). Consequently, the activations of caspase- 9 and -3 are the key mediators of cell apoptosis $(12,28)$. In the current study, we demonstrated that vitexin inhibited the levels of Bcl-2 (Fig. 6B) which led to the disruption of $\Delta \Psi \mathrm{m}$ (Fig. 5A) in U937 cells. Importantly, vitexin stimulated caspase-9 and -3 activities (Fig. 4) and protein expressions (Fig. 6) in U937 cells. Pretreatment with z-VAD (a pan-caspase inhibitor) (Fig. 3A) and cyclosporine A (Fig. 5B) led to a decrease in vitexin-induced TUNEL positive cells, compared with cells treated alone. Hence, vitexin-provoked apoptosis could be inhibited via suppressing the mitochondrial and caspase-dependent pathways. Taken together, these results suggest the potential use of the antileukemia activity of vitexin and confirmed that vitexin may be used as a treatment for diseases such as leukemia. Our study is also in agreement with a previous study by Zhou et al addressing the biological activity and anticancer actions of vitexin in tumor cell lines (9). In conclusion, the induction of apoptotic cell death by vitexin in U937 human leukemia cells was detected as an activation of caspase-3, -7 and -9 (Fig. 7). Based on these experiments, we suggest that vitexin enhances the cytotoxicity and induces an apoptotic cell death in U937 human leukemia cells.

\section{Acknowledgements}

This study was partly supported by the grant-in-aid from the National Science Council, Republic of China (Taiwan) (NSC-101-2313-B-039-008).

\section{References}

1. Lin JP, Yang JS, Lin JJ, et al: Rutin inhibits human leukemia tumor growth in a murine xenograft model in vivo. Environ Toxicol 27: 480-484, 2012.

2. Yang YL, Hung CC, Chen JS, et al: IKZF1 deletions predict a poor prognosis in children with B-cell progenitor acute lymphoblastic leukemia: a multicenter analysis in Taiwan. Cancer Sci 102: 1874-1881, 2011.

3. Lowenberg B, Downing JR and Burnett A: Acute myeloid leukemia. N Engl J Med 341: 1051-1062, 1999.

4. Lee SJ, Kim KH, Park JS, et al: Comparative analysis of cell surface proteins in chronic and acute leukemia cell lines. Biochem Biophys Res Commun 357: 620-626, 2007.

5. Stahnke K, Eckhoff S, Mohr A, Meyer LH and Debatin KM: Apoptosis induction in peripheral leukemia cells by remission induction treatment in vivo: Selective depletion and apoptosis in a $\mathrm{CD} 34^{+}$subpopulation of leukemia cells. Leukemia 17 : 2130-2139, 2003

6. Olsson I, Bergh G, Ehinger M and Gullberg U: Cell differentiation in acute myeloid leukemia. Eur J Haematol 57: 1-16, 1996.

7. Lu CC, Yang JS, Chiang JH, et al: Novel quinazolinone MJ-29 triggers endoplasmic reticulum stress and intrinsic apoptosis in murine leukemia WEHI-3 cells and inhibits leukemic mice. PLoS One 7: e36831, 2012.

8. Tsai JC, Huang GJ, Chiu TH, et al: Antioxidant activities of phenolic components from various plants of Desmodium species. Afr J Pharm Pharmacol 5: 468-476, 2011.

9. Zhou Y, Liu YE, Cao J, et al: Vitexins, nature-derived lignan compounds, induce apoptosis and suppress tumor growth. Clin Cancer Res 15: 5161-5169, 2009.

10. Banskota AH, Tezuka Y, Adnyana IK, et al: Hepatoprotective effect of combretum quadrangulare and its constituents. Biol Pharm Bull 23: 456-460, 2000. 
11. Kelloff GJ, Crowell JA, Steele VE, et al: Progress in cancer chemoprevention: Development of diet-derived chemopreventive agents. J Nutr 130: 467S-471S, 2000.

12. Lavrik IN, Golks A and Krammer PH: Caspases: pharmacological manipulation of cell death. J Clin Invest 115: 2665-2672, 2005.

13. Cory S, Huang DC and Adams JM: The Bcl-2 family: roles in cell survival and oncogenesis. Oncogene 22: 8590-8607, 2003.

14. Klampfer L, Cammenga J, Wisniewski HG and Nimer SD: Sodium salicylate activates caspases and induces apoptosis of myeloid leukemia cell lines. Blood 93: 2386-2394, 1999.

15. Aggarwal BB, Van Kuiken ME, Iyer LH, Harikumar KB and Sung B: Molecular targets of nutraceuticals derived from dietary spices: Potential role in suppression of inflammation and tumorigenesis. Exp Biol Med 234: 825-849, 2009.

16. Yang JS, Hour MJ, Huang WW, Lin KL, Kuo SC and Chung JG: MJ-29 inhibits tubulin polymerization, induces mitotic arrest, and triggers apoptosis via cyclin-dependent kinase 1-mediated Bcl-2 phosphorylation in human leukemia U937 cells. J Pharmacol Exp Ther 334: 477-488, 2010.

17. Chang YH, Yang JS, Kuo SC and Chung JG: Induction of mitotic arrest and apoptosis by a novel synthetic quinolone analogue, CWC-8, via intrinsic and extrinsic apoptotic pathways in human osteogenic sarcoma U-2 OS cells. Anticancer Res 29: 3139-3148, 2009.

18. Chiang JH, Yang JS, Ma CY, et al: Danthron, an anthraquinone derivative, induces DNA damage and caspase cascades-mediated apoptosis in SNU-1 human gastric cancer cells through mitochondrial permeability transition pores and Bax-triggered pathways. Chem Res Toxicol 24: 20-29, 2011.

19. Lu CC, Yang JS, Huang AC, et al: Chrysophanol induces necrosis through the production of ROS and alteration of ATP levels in J5 human liver cancer cells. Mol Nutr Food Res 54: 967-976, 2010 .
20. Kuo CL, Wu SY, Ip SW, et al: Apoptotic death in curcumintreated NPC-TW 076 human nasopharyngeal carcinoma cells is mediated through the ROS, mitochondrial depolarization and caspase-3-dependent signaling responses. Int J Oncol 39: 319-328, 2011.

21. Chung JG, Yang JS, Huang LJ, et al: Proteomic approach to studying the cytotoxicity of YC-1 on U937 leukemia cells and antileukemia activity in orthotopic model of leukemia mice. Proteomics 7: 3305-3317, 2007.

22. Wu PP, Liu KC, Huang WW, et al: Triptolide induces apoptosis in human adrenal cancer NCI-H295 cells through a mitochondrialdependent pathway. Oncol Rep 25: 551-557, 2011

23. Huang WW, Chiu YJ, Fan MJ, et al: Kaempferol induced apoptosis via endoplasmic reticulum stress and mitochondriadependent pathway in human osteosarcoma U-2 OS cells. Mol Nutr Food Res 54: 1585-1595, 2010.

24. Lee H, Park MT, Choi BH, et al: Endoplasmic reticulum stress-induced JNK activation is a critical event leading to mitochondria-mediated cell death caused by $\beta$-lapachone treatment. PLoS One 6: e21533, 2011.

25. Dong L, Fan Y, Shaox and Chen Z: Vitexin protects against myocardial ischemia/reperfusion injury in Langendorff-perfused rat hearts by attenuating inflammatory response and apoptosis. Food Chem Toxicol 49: 3211-3216, 2011.

26. Kim R, Emi M, Tanabe K and Murakami S: Role of the unfolded protein response in cell death. Apoptosis 11: 5-13, 2006.

27. Breckenridge DG, Germain M, Mathai JP, Nguyen $M$ and Shore GC: Regulation of apoptosis by endoplasmic reticulum pathways. Oncogene 22: 8608-8618, 2003.

28. Orrenius S: Reactive oxygen species in mitochondria-mediated cell death. Drug Metab Rev 39: 443-455, 2007. 